\title{
Dietary fatty acid intake is associated with paraoxonase 1 activity in a cohort-based analysis of 1,548 subjects
}

Daniel Seung Kim ${ }^{1,2}$, Sean K Maden ${ }^{1}$, Amber A Burt ${ }^{1}$, Jane E Ranchalis ${ }^{1}$, Clement E Furlong ${ }^{1,2}$ and Gail P Jarvik ${ }^{1,2^{*}}$

\begin{abstract}
Background: Paraoxonase 1 (PON1) is a cardioprotective, HDL-associated glycoprotein enzyme with broad substrate specificity. Our previous work found associations between dietary cholesterol and vitamin C with PON1 activity. The goal of this study was to determine the effect of specific dietary fatty acid (DFA) intake on PON1 activity.

Methods: 1,548 participants with paraoxonase activity measures completed the Harvard Standardized Food Frequency Questionnaire to determine their daily nutrient intake over the past year. Eight saturated, 3 monounsaturated, and 6 polyunsaturated DFAs were measured by the questionnaire. To reduce the number of observations tested, only specific fatty acids that were not highly correlated $(r<0.8)$ with other DFAs or that were representative of other DFAs through high correlation within each respective group (saturated, monounsaturated, or polyunsaturated) were retained for analysis. Six specific DFA intakes - myristic acid (14 carbon atoms, no double bonds - 14:0), oleic acid (18:1), gadoleic acid (20:1), a-linolenic acid (18:3), arachidonic acid (20:4), and eicosapentaenoic acid (20:5) - were carried forward to stepwise linear regression, which evaluated the effect of each specific DFA on covariate-adjusted PON1 enzyme activity.
\end{abstract}

Results: Four of the 6 tested DFA intakes - myristic acid $(p=0.038)$, gadoleic acid $\left(p=6.68 \times 10^{-7}\right)$, arachidonic acid $(p=0.0007)$, and eicosapentaenoic acid $(p=0.013)$ - were independently associated with covariate-adjusted PON1 enzyme activity. Myristic acid, a saturated fat, and gadoleic acid, a monounsaturated fat, were both positively associated with PON1 activity. Both of the tested polyunsaturated fats, arachidonic acid and eicosapentaenoic acid, were negatively associated with PON1 activity.

Conclusions: This study presents the largest cohort-based analysis of the relationship between dietary lipids and PON1 enzyme activity. Further research is necessary to elucidate and understand the specific biological mechanisms, whether direct or regulatory, through which DFAs affect PON1 activity.

Keywords: Paraoxonase 1, Dietary fatty acid intake, Saturated fats, Monounsaturated fats, Polyunsaturated fats, $\omega-3$ fatty acids, Cardiovascular disease

\footnotetext{
*Correspondence: pair@u.washington.edu

'Department of Medicine, Division of Medical Genetics, University of Washington School of Medicine, Box 357720, Seattle, WA 98195-7720, USA

${ }^{2}$ Department of Genome Sciences, University of Washington School of Medicine, Seattle, WA, USA
} reproduction in any medium, provided the original work is properly cited. The Creative Commons Public Domain Dedication waiver (http://creativecommons.org/publicdomain/zero/1.0/) applies to the data made available in this article, unless otherwise stated. 


\section{Background}

The beneficial effects of high-density lipoprotein (HDL) on cardiovascular health have recently come under increased scrutiny after both a large randomized clinical trial [1] and separate Mendelian randomization study [2] failed to show cardioprotective effects from raising HDL cholesterol levels (HDL-C) alone. Instead, focus has shifted to the atherosclerosis-related aspects of $\mathrm{HDL}$ biology that are not reflected in HDL-C measurements, such as paraoxonase 1 (PON1) activity.

PON1 is a glycoprotein enzyme with broad substrate specificity [3], which is at least partly responsible for the inhibitory and cardioprotective effects of HDL on lipid peroxidation and its resulting atherogenesis [4]. In addition to its cardioprotective effects, PON1 is protective against exposure to toxic organophosphorus (OP) compounds [5]. The activity of PON1 is measured by its catalytic efficiency for the hydrolysis of the substrates paraoxon (POase), diazoxon (DZOase), and phenylacetate (AREase). Of these measurements of PON1 activity, AREase is the most correlated with protein levels, as it is not drastically affected by the $P O N 1_{Q 192 R}$ coding polymorphism [6,7].

Four well-known human polymorphisms affect PON1 activity: $P O N 1_{C-108 T}$ (rs705379), PON1 $1_{G-162 A}$ (rs705381), $P O N 1_{M 55 L}$ (rs854560), and $P O N 1_{Q 192 R}$ (rs662). Of these, $P O N 1_{C-108 T}$ has the largest effect on PON1 AREase activity due its promoter-altering properties [8-11], accounting for approximately $15 \%$ of PON1 AREase variance [12]. The $P O N 1_{\mathrm{Q} 192 \mathrm{R}}$ polymorphism [13] is the primary determinant of toxic OP compound catalysis, accounting for over $65 \%$ of PON1 POase activity [12]. Rare protein-truncating and missense mutations in PON1 have been identified and associated with PON1 activity $[14,15]$.

Numerous environmental factors, including diet, have been associated with differential PON1 activity [16,17]. However, while dietary cholesterol is associated with PON1 activity in humans [18], the relationship between dietary fatty acid (DFA) intake and PON1 remains unclear. For example, rats fed a diet rich in oleic acid, a monounsaturated DFA (a fatty acid containing only a single double bond in its carbon chain) found in olive oil, had increased PON1 activity (+46\%); however, when the rats were switched to a diet high in polyunsaturated, $\omega-3$ and $\omega-6$ DFAs, there was a significant decrease in PON1 activity (-39\%) [19]. Similarly, human studies have found an increase in PON1 activity in 14 diabetic patients after meals rich in thermally stressed olive oil, with the effect greater in females than males [20]. Similarly, oleic acid intake, as determined from a 12-hour food recall survey, was found to be associated with increased PON1 activity, although the effect was only significant in subjects with the homozygous "RR" genotype at $P O N 1_{Q 192 R}$ [21]. Finally, a decrease in PON1 activity in both healthy men and women when switching from a diet rich in saturated fats to one composed primarily of trans DFAs has been reported [22].

Research into the in vitro interaction of PON1 and DFAs have similarly presented conflicting results. Negatively charged lipids, including saturated, monounsaturated, and polyunsaturated DFAs, have all been reported to inhibit PON1 enzyme activity in vitro [23], with polyunsaturated fatty acids having the largest inhibitory effect [24]. However, monounsaturated fatty acids (and to a lesser extent, saturated fats) have also been shown to protect PON1 from ascorbate/copper-mediated oxidative inactivation [24,25]. Notably, polyunsaturated fats prevented this monounsaturated DFA-dependent oxidative protective effect [24]. In addition, monounsaturated fats have been reported to preserve PON1 enzyme activity during lengthy in vitro incubation periods [24].

The Carotid Lesion Epidemiology and Risk (CLEAR) cohort is a Seattle-based carotid artery disease (CAAD) case-control cohort, comprised primarily of veterans, collected to identify risk factors for CAAD, CAAD progression, and other atherosclerotic disease end-points. Previous work in the CLEAR cohort has identified novel dietary factors - vitamins C and E [26], cholesterol intake [18], and dietary iron in non-anemic subjects [18] which are associated with PON1 enzyme activity. The majority of human studies examining the relationship between DFAs and PON1 have been small ( $\mathrm{n}<100$ subjects), and the in vitro evidence conflicting. Thus, the goal of the present study was to evaluate the effects of specific DFA intakes on PON1 activity as measured by AREase within this cohort of 1548 subjects, to elucidate the relationship of fatty acids and PON1.

\section{Methods}

\section{Ethics statement}

Institutional review boards at the University of Washington, Virginia Mason Medical Center, and Veterans Affairs Puget Sound approved the CLEAR study. Written, informed consent was obtained from each participant of the study.

\section{Sample}

The study population for this analysis consisted of 1,548 participants from the previously described CLEAR study $[27,28]$. The cohort consisted of 380 participants with CAAD as determined by ultrasound $(>50 \%$ stenosis in either carotid artery), 73 participants with moderate obstruction (15-49\% obstruction in at least one carotid artery), 96 subjects with other phenotypes, including peripheral artery disease (PAD) and coronary artery disease (CHD), and 999 controls $(<15 \%$ carotid stenosis bilaterally and absence of PAD and CHD). Current smoking status and reported ancestry were obtained by self-report. Insulin use was determined via self-report 
matched to hospital pharmacy records. Exclusion criteria included familial hypercholesterolemia, total fasting cholesterol greater than $400 \mathrm{mg} / \mathrm{dl}$, hypocoagulable state and/or the use of anticoagulant medication, post-organ transplant, or the inability to consent. Descriptive statistics of the studied subset of the CLEAR study are presented in Table 1.

\section{PON1 genotyping and phenotyping}

The four PON1 polymorphisms with the largest effects on PON1 enzyme activity, PON1 $1_{C-108 T} P O N 1_{G-162 A}$, $P O N 1_{M 55 L}$ and $P O N 1_{Q 192 R}$, were genotyped using previously described methods $[8,9]$. PON1 activity was measured by the rate of enzymatic degradation of phenylacetate (AREase) via a continuous spectrophotometric assay with lithium heparin plasma, as AREase is least affected by the $P O N 1_{Q 192 R}$ polymorphism and also is more closely related to PON1 protein levels [6,7]. PON1 AREase activity was measured in triplicate and averaged for analysis. Measurements were made blinded to phenotype and diet data.

\section{Food-frequency questionnaire}

At enrollment, participants were asked to complete the standardized Harvard food frequency questionnaire

\section{Table 1 Baseline characteristics of the studied subset of the CLEAR cohort}

\begin{tabular}{|c|c|}
\hline Baseline characteristics & $\begin{array}{l}\text { CLEAR cohort } \\
(\mathrm{N}=1548)\end{array}$ \\
\hline \multicolumn{2}{|l|}{ Ethnicity, n (\%) } \\
\hline European ancestry, not Hispanic & $1240(80.1)$ \\
\hline Hispanic ancestry & $36(2.3)$ \\
\hline African ancestry & $128(8.3)$ \\
\hline Asian/Pacific Islander ancestry & $144(9.3)$ \\
\hline \multicolumn{2}{|l|}{ Gender, n (\%) } \\
\hline Female & $544(35.1)$ \\
\hline Male & $1004(64.9)$ \\
\hline Age, mean $\pm S D$, years & $64.84 \pm 9.69$ \\
\hline Current smoker, n (\%) & $179(11.6)$ \\
\hline \multicolumn{2}{|l|}{ Dietary fat intake } \\
\hline \multicolumn{2}{|l|}{ Saturated fats } \\
\hline In(Myristic acid (14:0) intake), mean \pm SD, g/day & $1.03 \pm 0.339$ \\
\hline \multicolumn{2}{|l|}{ Monounsaturated fats } \\
\hline In(Oleic acid (18:1) intake), mean \pm SD, g/day & $3.14 \pm 0.419$ \\
\hline In(Gadoleic acid (20:1) intake), mean \pm SD, g/day & $0.242 \pm 0.143$ \\
\hline \multicolumn{2}{|l|}{ Polyunsaturated fats } \\
\hline In(a-Linolenic acid (18:3) intake), mean $\pm S D, g /$ day & $0.795 \pm 0.239$ \\
\hline In(Arachidonic acid (20:4) intake), mean \pm SD, g/day & $0.140 \pm 0.0666$ \\
\hline In(Eicosapentaenoic acid (20:5) intake), mean \pm SD, g/day & $0.138 \pm 0.123$ \\
\hline PON1 AREase activity, mean \pm SD, IU & $149.58 \pm 50.47$ \\
\hline
\end{tabular}

developed by the Health Professionals Follow-Up Study (https://regepi.bwh.harvard.edu/health/nutrition.html). The survey asked participants for their average frequency of intake of specified portions of 131 foods, vitamins, and mineral supplements. The surveys were then returned to Harvard School of Public Health and the Brigham and Women's Hospital, where they underwent quantitative analysis to return the inferred average intake of all micronutrients, including DFAs, vitamins, and minerals. The Harvard Food Frequency Questionnaire has been validated against two, in-depth, 1-week diet records taken approximately six months apart [29]. Additionally, the inferred intake of dietary fats have been validated against plasma lipid measurements $[30,31]$.

\section{DFA selection}

To reduce the number of statistical tests, only DFAs not highly correlated $(r<0.8)$ with other DFAs or that were representative of other DFAs through high correlation within each fatty acid group (saturated, monounsaturated, and polyunsaturated) were carried forward to statistical testing, as presented in Figure 1. Linear correlation within each fatty acid group was assessed by Pearson's correlation coefficient ( $\mathrm{r}$ ). Of the 8 saturated DFAs measured by the food frequency questionnaire, all were highly correlated with myristic acid, composed of 14 carbons and no double bonds (14:0). Within the monounsaturated (fatty acids with one double bond) fatty acid group, palmitoleic (16:1) and oleic acid (18:1) were highly correlated with each other, while the third member, gadoleic acid (20:1) was not strongly correlated with either. Due to prior reports in the literature of a positive association between oleic acid and PON1 activity [19,20,24], oleic and gadoleic acid were carried forward to statistical testing. Within the polyunsaturated fat group, there were 3 clusters of correlation (see Figure 1). From these correlation blocks, $\alpha$-linolenic acid (18:3, a $\omega-3$ DFA), arachidonic acid (20:4, a $\omega-6$ DFA), and eicosapentaenoic acid (20:5, a $\omega-3$ DFA) moved on to the stepwise linear regression procedure.

\section{Statistical methods}

Natural log transformation was performed for each of the 6 specific DFA intake variables, as they all displayed a skewed distribution. Extreme observations were Winsorized to 3 standard deviations from the mean [32]. For food frequency data, participants were excluded if their caloric intake was $<800$ calories/day or $>4000$ calories/day. Additionally, participants were excluded if the returned survey had $\geq 70$ missing items.

All analyses were performed in R (http://www.r-project.org/). Genotypes were coded using an additive model. Stepwise linear regression was performed with the 6 specific DFA intake variables entering the model. Model comparison was performed using Akaike's 


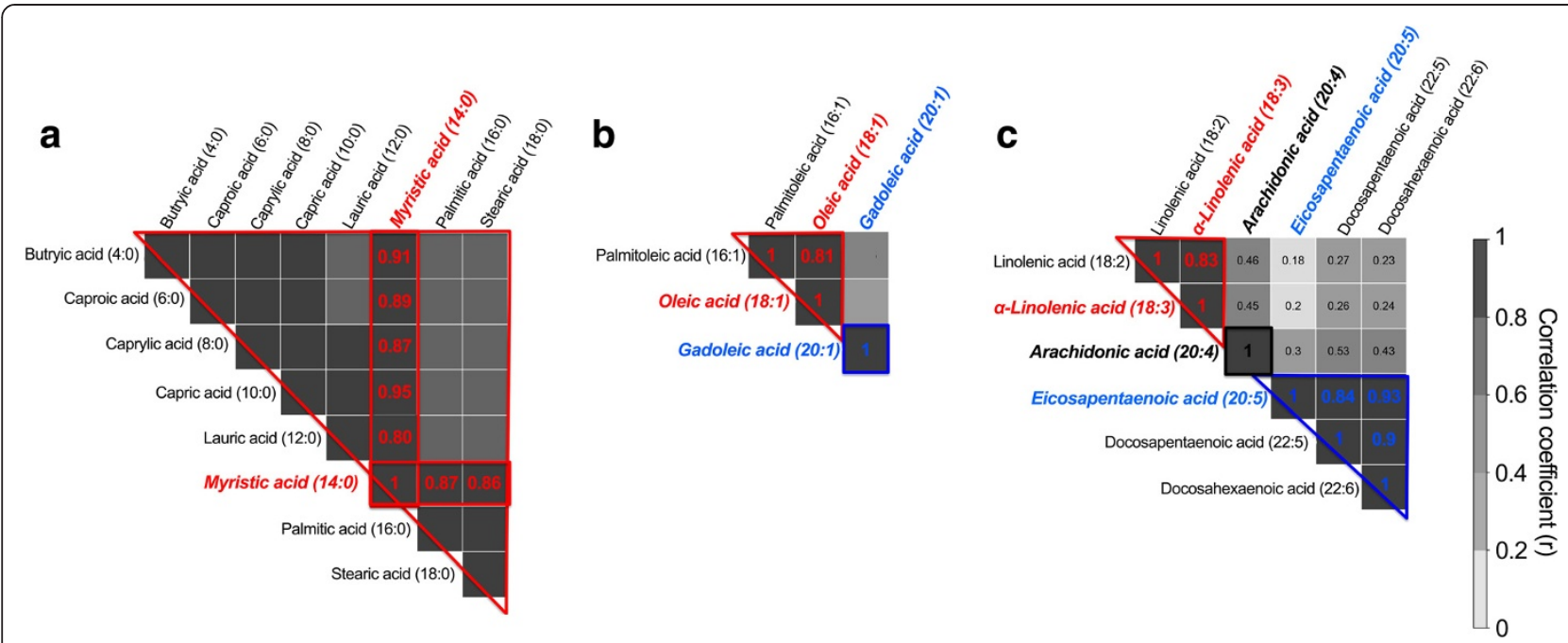

Figure 1 Selection of specific dietary fatty acid intakes for analysis by correlation. Correlation matrix between specific dietary fatty acids within the group of saturated (a), monounsaturated (b), and polyunsaturated fatty acids (c). To reduce the number of statistical tests, only those dietary fatty acids not highly correlated (Pearson's pairwise correlation coefficient, $r,<0.8$ ) with others in its group were carried forward to analysis. If numerous fatty acid intakes were highly correlated $(r \geq 0.8)$, a single representative was chosen.

information criterion (AIC), beginning with a base model that included age, sex, current smoking status, self-reported race (with European ancestry as the reference group, as they comprised the majority of the cohort), and the genotypes of the 4 functional PON1 polymorphisms as covariates for the prediction of PON1 AREase activity. Only specific DFA intakes that improved model prediction of the outcome PON1 AREase activity were retained in the final model. To identify whether DFAs account for variance previously explained by dietary cholesterol or other variables, a secondary analysis in the previously published subset of the cohort ( $\mathrm{n}=1402$ participants) was performed; in addition to the effects of dietary cholesterol, vitamin $\mathrm{C}$, folate, iron, and insulin use on PON1 activity that had previously been reported to be significant in this subset [18].

\section{Results}

Demographic, clinical, and dietary fat intake variables are presented in Table 1. Participants of self-reported European, non-Hispanic ancestry composed the majority of the cohort (80.1\%). Subjects of Asian (9.3\%), African (8.3\%), and Hispanic (2.3\%) ancestry composed the remainder of the cohort. Males accounted for approximately two-thirds $(64.9 \%)$ of the studied population. The average age of all subjects was 64.8 years, and $11.6 \%$ of the cohort were current smokers. PON1 AREase activity had a mean of 149.6 IU with a standard deviation of 50.5 forming an approximate normal distribution.

To reduce the number of statistical tests performed and problems with colinearity, only 6 of the 17 available DFA intakes were selected for stepwise linear regression.
The 6 selected DFAs were highly correlated with other DFAs in each group (saturated, monounsaturated, polyunsaturated) and therefore captured the majority of the group variation while minimizing the problems that arise with colinearity. The 6 selected DFAs were: myristic acid (14:0, saturated fat), oleic acid (18:1, monounsaturated fat), gadoleic acid (20:1, monounsaturated fat), $\alpha$-linolenic acid (18:3, polyunsaturated $\omega-3$ fat), arachidonic acid (20:4, polyunsaturated $\omega-6$ fat), and eicosapentaenoic acid (20:5, polyunsaturated $\omega-3$ fat). The correlation between the selected DFAs and the other DFAs in each group are summarized in Figure 1.

A baseline regression model containing the 4 functional PON1 variants $\left(P O N 1_{C-1087} P O N 1_{G-162 A}, P O N 1_{M 55 L}\right.$ and $\left.P O N 1_{Q 192 R}\right)$, age, sex, current smoking status, and genetic ancestry explained $25.1 \%$ of PON1 AREase variance. We then examined a best-fit model using stepwise linear regression with the base model and the 6 DFAs identified through correlation testing. Only those DFAs that improved model prediction through assessment by AIC were retained in the final, best-fit regression model.

In the best-fit regression model, 4 of the 6 DFA intakes were retained in addition to the base model, together explaining 26.3\% of PON1 AREase activity (see Table 2). The 4 specific DFAs (myristic acid $(\mathrm{p}=0.038)$, gadoleic acid $\left(\mathrm{p}=6.68 \times 10^{-7}\right)$, arachidonic acid $(\mathrm{p}=0.00069)$, and eicosapentaenoic acid $(\mathrm{p}=0.0134))$ serially explained $0.25 \%, 0.58 \%, 0.61 \%$, and $0.29 \%$ of PON1 AREase activity, respectively. Myristic acid (beta coefficient $=7.71$ ), a saturated fat, and gadoleic acid (beta coefficient $=59.50$ ), a monounsaturated fat, were both significantly positively associated with an increase in PON1 AREase activity. 
Table 2 Best-fit model from stepwise linear regression predicting PON1 AREase activity using dietary fat intake variables ( $\mathrm{n}=1548$ subjects)

\begin{tabular}{|c|c|c|c|}
\hline Variable $^{a, b}$ & Estimate $\pm \mathrm{SE}$ & $\%$ PON1 AREase variation & $P$ \\
\hline (Intercept) & $236.85 \pm 9.57$ & - & $<2 \times 10^{-16}$ \\
\hline$P O N 1_{C-108 T}$ & $-26.48 \pm 1.94$ & $13.30 \%$ & $<2 \times 10^{-16}$ \\
\hline$P O N 1_{G-162 A}$ & $-1.31 \pm 2.24$ & $0.21 \%$ & 0.56 \\
\hline$P O N 1_{Q 192 R}$ & $-12.34 \pm 2.08$ & $2.38 \%$ & $3.83 \times 10^{-9}$ \\
\hline$P O N 1_{M 55 L}$ & $-6.16 \pm 2.16$ & $0.42 \%$ & 0.0044 \\
\hline Age & $-0.94 \pm 0.12$ & $2.81 \%$ & $5.54 \times 10^{-15}$ \\
\hline Sex & $17.95 \pm 2.42$ & $4.70 \%$ & $2.17 \times 10^{-13}$ \\
\hline Current smoker & $-13.43 \pm 3.58$ & $0.44 \%$ & 0.00018 \\
\hline Hispanic ancestry ${ }^{c}$ & $2.43 \pm 7.40$ & $0.01 \%$ & 0.74 \\
\hline African ancestry ${ }^{c}$ & $-17.04 \pm 4.52$ & $0.71 \%$ & 0.00017 \\
\hline Asian ancestry ${ }^{c}$ & $-5.55 \pm 4.278$ & $0.13 \%$ & 0.19 \\
\hline In(Myristic acid (14:0) intake) & $7.71 \pm 3.71$ & $0.25 \%$ & 0.038 \\
\hline In(Gadoleic acid (20:1) intake) & $59.50 \pm 11.92$ & $0.58 \%$ & $6.68 \times 10^{-7}$ \\
\hline In(Arachidonic acid (20:4) intake) & $-67.15 \pm 19.76$ & $0.61 \%$ & 0.00069 \\
\hline In(Eicosapentaenoic acid (20:5) intake) & $-33.01 \pm 13.33$ & $0.29 \%$ & 0.013 \\
\hline
\end{tabular}

${ }^{\mathrm{a}}$ In(Oleic acid (18:1) intake) was not significantly associated with PON1 AREase activity $(p=0.246$, beta coefficient $=3.52)$ and was not retained in the final stepwise regression model.

${ }^{b}$ In ( $a$-Linolenic acid (18:3) intake) was not significantly associated with PON1 AREase activity $(p=0.913$, beta coefficient $=-0.579)$ and was not retained in the final stepwise regression model.

${ }^{\circ}$ Genetic ancestry coded as dummy variable, with European ancestry (the majority of the CLEAR cohort) subset used as the reference group.

Conversely, dietary intake of the two polyunsaturated fats, arachidonic acid (beta coefficient $=-67.15$ ) and eicosapentaenoic acid (beta coefficient $=-33.01$ ), were both significantly negatively associated with PON1 AREase activity. Sensitivity analyses stratifying by sex and CAAD status did not reveal significant differences in subgroup coefficient sizes or p-values, suggesting that these factors were not affecting the relationship between specific DFA intake and PON1 enzyme activity.

To determine whether the PON1 activity-DFA association was related to the prior report of an association with dietary cholesterol in this cohort, we performed a secondary analysis in the previously published subset of the cohort ( $\mathrm{n}=1402$ participants), in which an association between dietary factors including cholesterol and PON1 activity was detected [5,18]. Gadoleic $(r=0.33)$, myristic $(r=0.64)$ and arachidonic acid $(r=0.82)$ were significantly correlated $(\mathrm{p}<0.001)$ with dietary cholesterol intake, while eicosapentaenoic acid $(r=0.16)$ was not.

In the best-fit model, $36.5 \%$ of PON1 AREase activity was explained, as opposed to $35.04 \%$ when DFAs were not included in the model (see Table 3 for specific model coefficients and p-values and Figure 2 for a summary of PON1 AREase activity explained). All 6 previously reported dietary and clinical variables that affected PON1 AREase activity (dietary cholesterol, vitamin C, folate, iron, alcohol intake, and insulin use) were retained in the final model in addition to the 4 specific DFA intakes. Addition of dietary DFA to the model reduced the coefficient of the dietary cholesterol effect by approximately $10 \%$ (from 59.70 to 56.41 ) and the variance explained by dietary cholesterol from 5.45 to $4.98 \%$. Similarly, the effect sizes of gadoleic (from 59.50 to 46.78) and arachidonic acid (from -67.15 to -34.17 ) decreased by $21.4 \%$ and $49.1 \%$, respectively, with dietary cholesterol intake in the model. However, DFAs accounted for $1.2 \%$ of PON1 activity variance; thus, the total variance explained by dietary cholesterol and DFAs was greater than for dietary cholesterol alone.

\section{Discussion}

PON1 is an HDL-associated enzyme that is involved in numerous human disease-related pathways. PON1 is atheroprotective $[4,33]$, an antioxidant $[34,35]$, can help to decrease the lethality of Pseudomonas aeruginosa infections [36,37], and it hydrolyzes numerous compounds - including pharmacologic agents $[3,17,38]$ and toxic organophosphorus compounds $[39,40]$. A full understanding of PON1 should include the dietary factors that affect its expression and activity $[18,26]$.

In the current study, we analyzed what we believe to be the largest cohort with both dietary intake and PON1 enzyme activity data, and report that the monounsaturated DFA, gadoleic acid (20:1), is strongly associated with an increase in PON1 activity. We also observed a strong decrease in PON1 enzyme activity associated with increasing polyunsaturated fat intake of arachidonic (20:4) and eicosaepentaenoic (20:5) acid. Finally, we 
Table 3 Best-fit model from stepwise linear regression predicting PON1 AREase activity using both dietary fat and other intake variables $(n=1402$ subjects)

\begin{tabular}{|c|c|c|c|}
\hline Variable & Estimate \pm SE & $\%$ PON1 AREase variation & $P$ \\
\hline (Intercept) & $-71.40 \pm 35.70$ & - & 0.046 \\
\hline PON1 $1_{C-108 T}$ & $-27.99 \pm 2.13$ & $13.61 \%$ & $<2 \times 10^{-16}$ \\
\hline$P O N 1_{G-162 A}$ & $-2.42 \pm 2.40$ & $0.11 \%$ & 0.31 \\
\hline PON1 Q192R & $-12.73 \pm 2.24$ & $1.92 \%$ & $1.73 \times 10^{-8}$ \\
\hline PON1 $1_{\text {M5L }}$ & $-5.50 \pm 2.31$ & $0.54 \%$ & 0.017 \\
\hline Age & $-0.808 \pm 0.135$ & $3.57 \%$ & $2.89 \times 10^{-9}$ \\
\hline Sex & $16.88 \pm 2.77$ & $5.45 \%$ & $1.49 \times 10^{-9}$ \\
\hline Current smoker & $-15.34 \pm 3.88$ & $0.70 \%$ & $8.24 \times 10^{-5}$ \\
\hline Hispanic ancestry & $6.06 \pm 8.27$ & $0.001 \%$ & 0.46 \\
\hline African ancestry & $-12.99 \pm 5.02$ & $0.58 \%$ & 0.0097 \\
\hline Asian ancestry & $-5.44 \pm 5.29$ & $0.015 \%$ & $0.30 ?$ \\
\hline Insulin use & $-13.07 \pm 5.76$ & $1.02 \%$ & 0.023 \\
\hline In(Dietary cholesterol) $)^{a, b, c}$ & $53.41 \pm 6.22$ & $4.98 \%$ & $<2 \times 10^{-16}$ \\
\hline Alcohol category & $6.27 \pm 1.17$ & $1.84 \%$ & $1.11 \times 10^{-7}$ \\
\hline In(Vitamin C) & $4.73 \pm 1.51$ & $0.23 \%$ & 0.0018 \\
\hline Iron & $-0.219 \pm 0.0794$ & $0.54 \%$ & 0.0057 \\
\hline Folate & $-0.00904 \pm 0.00466$ & $0.19 \%$ & 0.053 \\
\hline In(Myristic acid (14:0) intake) ${ }^{a}$ & $8.95 \pm 4.05$ & $0.41 \%$ & 0.027 \\
\hline In(Gadoleic acid (20:1) intake) ${ }^{b}$ & $46.78 \pm 12.60$ & $0.27 \%$ & 0.00021 \\
\hline In(Arachidonic acid (20:4) intake) ${ }^{c}$ & $-34.17 \pm 21.56$ & $0.15 \%$ & 0.11 \\
\hline In(Eicosapentaenoic acid (20:5) intake) & $-36.96 \pm 14.24$ & $0.36 \%$ & 0.0096 \\
\hline
\end{tabular}

${ }^{a} \operatorname{In}$ (Dietary cholesterol) was significantly correlated $(p<0.001)$ with $\ln ($ Myristic acid) $(r=0.64)$.

${ }^{b} \ln ($ Dietary cholesterol) was significantly correlated $(p<0.001)$ with $\ln$ (Gadoleic acid) $(r=0.33)$.

In(Dietary cholesterol) was significantly correlated $(p<0.001)$ with $\ln ($ Arachidonic acid) $(r=0.82)$.

report a proportionally smaller, though significant, effect of the saturated fat, myristic acid (14:0), on PON1 AREase activity. "We note that when considering previously reported dietary variables, the addition of DFA intake explained an additional $1.2 \%$ of PON1 AREase activity. Although $1.2 \%$ of PON1 activity may seem modest, it compares well to the scale of effects found for complex traits, including lipids [41]. Moreover, this data may reveal a new biological avenue for investigation regarding the potential regulation of PON1 by the dietary intake of fatty acids; namely, whether the mechanism through which DFAs intake affects PON1 activity is through gene regulation, direct protein interaction, or other more indirect processes. Finally, due to the ubiquitous nature of PON1 in human disease and physiology [17], understanding even a small portion of its variance is of high importance.

Monounsaturated fats have been previously positively associated with PON1 activity in human [20,21] and animal [19] studies. Evidence from in vitro studies suggests that both saturated and monounsaturated fats bind to a specific and protective site, separate from the catalytic active site, to prevent inactivation of PON1 through oxidation [24,25].
Moreover, in vitro evidence suggests that this binding of saturated and monounsaturated fats decreases PON1 activity only marginally (approximately 10\%) [24]. The strongly protective effects of monounsaturated DFAs are broad: protection of PON1 from oxidation was not dependent on either carbon chain length or location of the double bond [24]. In our specific study, we did not find a strong association between oleic acid (the most commonly reported monounsaturated fat) and PON1 activity; when gadoleic acid was removed from the best-fit regression model, oleic acid was not significantly associated with PON1 activity (see Table 2). We did, however, find a strongly positive association of gadoleic acid (beta coefficient $=59.50, \mathrm{p}=6.68 \times$ $10^{-7}$ ) on PON1 activity. The exact molecular mechanism for our finding, though suggested, is yet unknown, as are possible other mechanisms, including potential effects on PON1 expression.

While the $\omega-3$ and $\omega-6$ DFAs commonly found in fish oil are generally thought to be cardioprotective [42], prior research has found fish oils, and the polyunsaturated fatty acids that compose fish oil, to be inhibitory to PON1 activity $[19,23,24]$. In vitro work suggests that polyunsaturated DFAs are recognized by the active site 


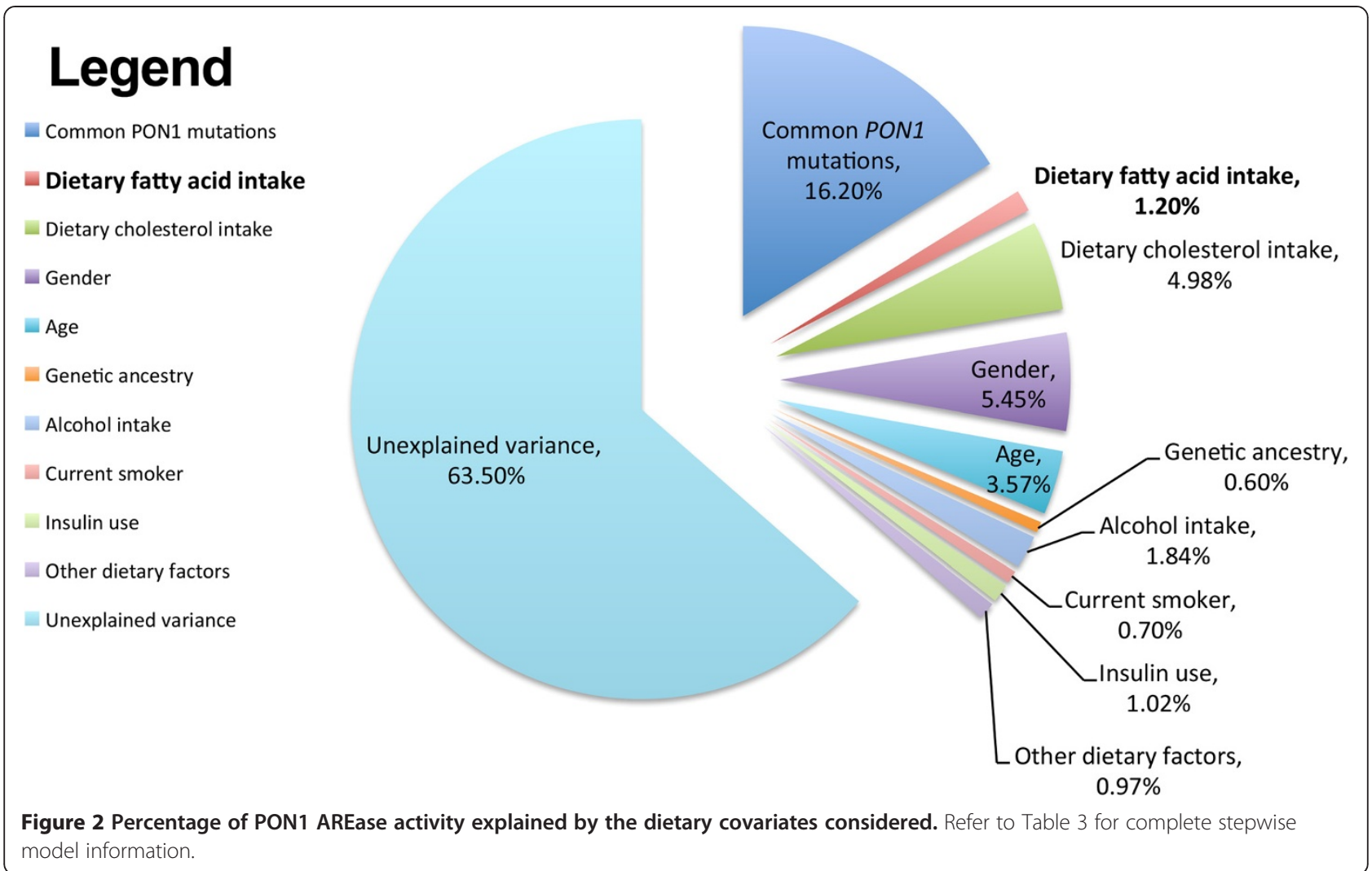

of PON1 and therefore act as competitive inhibitors of PON1 enzyme activity [24]. Moreover, binding of polyunsaturated fats appears to change the conformation of the protein, preventing protective binding of monounsaturated and saturated DFAs and, therefore, increasing the susceptibility of PON1 to inactivation from oxidation [24]. Consistent with prior report, we found that 2 (arachidonic and eicosaepentaenoic acid) of the 3 tested polyunsaturated DFAs were negatively associated with PON1 activity. The third polyunsaturated fatty acid, $\alpha-$ linolenic acid, trended negative, but was not significantly associated with PON1 activity (see Table 2). Thus, the cardioprotective effects of fish oil and polyunsaturated fats appear to occur in spite of what appear to be inhibitory effects on PON1 enzyme activity, whose activity is associated with atheroprotection.

When considering dietary intakes that we previously have reported [18], we were able to explain a total of $36.5 \%$ of PON1 AREase activity. However, we note that with the addition of these dietary covariates, there was a decrease in the magnitude of the beta coefficients and percentage of PON1 activity explained for both gadoleic acid and arachidonic acid. This likely is due to the highly significant correlation between both gadoleic $(r=0.33)$ and arachidonic $(\mathrm{r}=0.82)$ acid with dietary cholesterol intake. Dietary cholesterol intake was the third most predictive covariate (after $P O N 1_{C-108 T}$ and gender) and accounted for approximately
$5 \%$ of PON1 AREase activity. However, after accounting for the effects of dietary cholesterol intake, both gadoleic and arachidonic acid were retained in the best-fit stepwise regression model. This indicates that both DFAs have effects on PON1 activity that are independent of the large effects of dietary cholesterol intake and which aid in the prediction of PON1 AREase variance.

Strengths of this study include its large, wellcharacterized community-based cohort with dietary intake information, genetic data, and lipid phenotypes. To the best of the authors' knowledge, this is the largest analysis of the effects of DFAs on PON1 activity. Limitations include the lack of ethnic diversity and that the cohort was collected primarily for CAAD, with participants that tended to be older than the general population. Together, these limitations may limit the generalizations and applications of these findings. Finally, the food frequency questionnaire used had limited data on several dietary covariates of interest: namely, trans fats, which have previously been reported to be inhibitory to PON1 activity [22]. As a result, some DFA associations with PON1 could not be assessed in this analysis.

In conclusion, our study has identified and confirmed the effects of specific fatty acid intakes on PON1 activity in a large cohort collected for vascular disease. Specifically, we report the positive association of saturated fats 
(myristic acid, $\mathrm{p}=0.038$ ) and monounsaturated fats (gadoleic acid, $\mathrm{p}=6.68 \times 10^{-7}$ ) on PON1 AREase activity and the PON1 activity decreasing effects of the polyunsaturated fats, arachidonic $(p=0.00069)$ and eicosapentaenoic $(p=0.013)$ acid. When considered in conjunction with our previously reported dietary, genetic, and clinical covariates [18], we were able to explain $36.5 \%$ of PON1 AREase activity. Further work characterizing the $63.5 \%$ unexplained PON1 variance should consider the possible effects of rare PON1 variation $[14,15]$, epistasis of PON1 with other genes, and gene-byenvironment interactions [43] in the attempts to further understand the determinants of this important and multi-faceted enzyme.

\section{Competing interest}

The authors declare that they have no competing interests.

\section{Authors' contributions}

DSK, CEF, and GPJ came up with hypothesis and study design. JER performed laboratory analyses. DSK, SKM, and AAB performed statistical analyses. DSK, SKM, CEF, and GPJ wrote the manuscript. All authors read and approved the final manuscript.

\section{Acknowledgements}

This work was funded in part by National Institutes of Health RO1 HL67406 and a State of Washington Life Sciences Discovery Award (265508) to the Northwest Institute of Genetic Medicine. DSK was supported in part by the Benjamin and Margaret Hall Endowed Fellowship in Genome Sciences and National Institutes of Health 5T31HG000035-18 and 1F31MH101905-01.

Received: 23 September 2013 Accepted: 7 December 2013

Published: 12 December 2013

\section{References}

1. AlM-HIGH Investigators, Boden WE, Probstfield JL, Anderson T, Chaitman BR, Desvignes-Nickens P, Koprowicz K, McBride R, Teo K, Weintraub W: Niacin in patients with low $\mathrm{HDL}$ cholesterol levels receiving intensive statin therapy. N Engl J Med 2011, 365:2255-2267.

2. Voight BF, Peloso GM, Orho-Melander M, Frikke-Schmidt R, Barbalic M, Jensen MK, Hindy G, Hólm H, Ding EL, Johnson T: Plasma HDL cholesterol and risk of myocardial infarction: a mendelian randomisation study. Lancet 2012, 380:572-580.

3. Draganov DI, Teiber JF, Speelman A, Osawa Y, Sunahara R, La Du BN: Human paraoxonases (PON1, PON2, and PON3) are lactonases with overlapping and distinct substrate specificities. I Lipid Res 2005, 46:1239-1247.

4. Mackness MI, Arrol S, Abbott C, Durrington PN: Protection of low-density lipoprotein against oxidative modification by high-density lipoprotein associated paraoxonase. Atherosclerosis 1993, 104:129-135.

5. Costa LG, McDonald BE, Murphy SD, Omenn GS, Richter RJ, Motulsky AG, Furlong CE: Serum paraoxonase and its influence on paraoxon and chlorpyrifos-oxon toxicity in rats. Toxicol Appl Pharmacol 1990, 103:66-76.

6. Richter RJ, Jarvik GP, Furlong CE: Determination of paraoxonase 1 status without the use of toxic organophosphate substrates. Circ Cardiovasc Genet 2008, 1:147-152.

7. Richter RJ, Jarvik GP, Furlong CE: Paraoxonase 1 (PON1) status and substrate hydrolysis. Toxicol Appl Pharmacol 2009, 235:1-9.

8. Brophy VH, Hastings MD, Clendenning JB, Richter RJ, Jarvik GP, Furlong CE: Polymorphisms in the human paraoxonase (PON1) promoter. Pharmacogenetics 2001, 11:77-84

9. Brophy VH, Jampsa RL, Clendenning JB, McKinstry LA, Jarvik GP, Furlong CE: Effects of 5 ' regulatory-region polymorphisms on paraoxonase-gene (PON1) expression. Am J Hum Genet 2001, 68:1428.

10. Suehiro T, Nakamura T, Inoue M, Shiinoki T, Ikeda Y, Kumon Y, Shindo M, Tanaka H, Hashimoto K: A polymorphism upstream from the human paraoxonase (PON1) gene and its association with PON1 expression. Atherosclerosis 2000, 150:295-298.

11. Leviev I, James RW: Promoter polymorphisms of human paraoxonase PON1 gene and serum paraoxonase activities and concentrations. Arterioscler Thromb Vasc Biol 2000, 20:516-521.

12. Kim DS, Burt AA, Ranchalis JE, Richter RJ, Marshall JK, Eintracht JF, Rosenthal EA, Furlong CE, Jarvik GP: Additional common polymorphisms in the PON gene cluster predict PON1 activity but Not vascular disease. J Lipids 2012, 2012:476316.

13. Hassett C, Richter RJ, Humbert R, Chapline C, Crabb JW, Omiecinski CJ, Furlong CE: Characterization of CDNA clones encoding rabbit and human serum paraoxonase: the mature protein retains its signal sequence. Biochemistry 1991, 30:10141-10149.

14. Jarvik GP, Jampsa R, Richter RJ, Carlson CS, Rieder MJ, Nickerson DA, Furlong CE: Novel paraoxonase (PON1) nonsense and missense mutations predicted by functional genomic assay of PON1 status. Pharmacogenetics 2003, 13:291-295.

15. Kim DS, Burt AA, Crosslin DR, Robertson PD, Ranchalis JE, Boyko EJ, Nickerson DA, Furlong CE, Janvik GP: Novel common and rare genetic determinants of paraoxonase activity: FTO, SERPINA12, and ITGAL. J Lipid Res 2013, 54:552-560.

16. Costa $L G$, Giordano G, Furlong CE: Pharmacological and dietary modulators of paraoxonase 1 (PON1) activity and expression: the hunt goes on. Biochem Pharmacol 2011, 81:337-344.

17. Kim DS, Marsillach J, Furlong CE, Jarvik GP: Pharmacogenetics of paraoxonase activity: elucidating the role of high-density lipoprotein in disease. Pharmacogenomics 2013, 14:1495-1515.

18. Kim DS, Burt AA, Ranchalis JE, Richter RJ, Marshall JK, Nakayama KS, Jarvik ER, Eintracht JF, Rosenthal EA, Furlong CE, Jarvik GP: Dietary cholesterol increases paraoxonase 1 enzyme activity. J Lipid Res 2012, 53:2450-2458.

19. Kudchodkar BJ, Lacko AG, Dory L, Fungwe TV: Dietary fat modulates serum paraoxonase 1 activity in rats. J Nutr 2000, 130:2427-2433.

20. Wallace AJ, Sutherland WH, Mann J, Williams SM: The effect of meals rich in thermally stressed olive and safflower oils on postprandial serum paraoxonase activity in patients with diabetes. Eur J Clin Nutr 2001, 55:951-958.

21. Tomás M, Sentí M, Elosua R, Vila J, Sala J, Masià R, Marrugat J: Interaction between the Gln-Arg 192 variants of the paraoxonase gene and oleic acid intake as a determinant of high-density lipoprotein cholesterol and paraoxonase activity. Eur J Pharmacol 2001, 432:121-128.

22. de Roos NM, Schouten EG, Scheek LM, van Tol A, Katan MB: Replacement of dietary saturated fat with trans fat reduces serum paraoxonase activity in healthy men and women. Metab Clin Exp 2002, 51:1534-1537.

23. NGUYEN SD, Sok D-E: Preferential inhibition of paraoxonase activity of human paraoxonase 1 by negatively charged lipids. J Lipid Res 2004, 45:2211-2220.

24. NGUYEN SD, Sok D-E: Beneficial effect of oleoylated lipids on paraoxonase 1: protection against oxidative inactivation and stabilization. Biochem J 2003, 375:275-285.

25. NGUYEN SD, Hung ND, Cheon-Ho P, Ree KM, Dai-Eun S: Oxidative inactivation of lactonase activity of purified human paraoxonase 1 (PON1). Biochim Biophys Acta 2009, 1790:155-160.

26. Jarvik GP, Tsai NT, McKinstry LA, Wani R, Brophy VH, Richter RJ, Schellenberg GD, Heagerty PJ, Hatsukami TS, Furlong CE: Vitamin C and E intake is associated with increased paraoxonase activity. Arterioscler Thromb Vasc Biol 2002, 22:1329-1333.

27. Jarvik GP, Rozek LS, Brophy VH, Hatsukami TS, Richter RJ, Schellenberg GD, Furlong CE: Paraoxonase (PON1) phenotype is a better predictor of vascular disease than is PON1192 or PON155 genotype. Arterioscler Thromb Vasc Biol 2000, 20:2441-2447.

28. Jarvik GP, Hatsukami TS, Carlson C, Richter RJ, Jampsa R, Brophy VH, Margolin S, Rieder M, Nickerson D, Schellenberg GD: Paraoxonase activity, but not haplotype utilizing the linkage disequilibrium structure, predicts vascular disease. Arterioscler Thromb Vasc Biol 2003, 23:1465-1471.

29. Rimm EB, Giovannucci EL, Stampfer MJ, Colditz GA, Litin LB, Willett WC: Reproducibility and validity of an expanded self-administered semiquantitative food frequency questionnaire among male health professionals. Am J Epidemiol 1992, 135:1114-1126. discussion 1127-36.

30. Hunter DJ, Rimm EB, Sacks FM, Stampfer MJ, Colditz GA, Litin LB, Willett WC: Comparison of measures of fatty acid intake by subcutaneous fat aspirate, food frequency questionnaire, and diet records in a free-living population of US men. Am J Epidemiol 1992, 135:418-427. 
31. Willett W, Stampfer M, Chu NF, Spiegelman D, Holmes M, Rimm E: Assessment of questionnaire validity for measuring total fat intake using plasma lipid levels as criteria. Am J Epidemiol 2001, 154:1107-1112.

32. Dixon WJ, Tukey JW: Approximate behavior of the distribution of Winsorized t (Trimming/Winsorization 2). Technometrics 1968, 10:83-98.

33. Mackness MI, Arrol S, Durrington PN: Paraoxonase prevents accumulation of lipoperoxides in low-density lipoprotein. FEBS Lett 1991, 286:152-154.

34. Marsillach J, Mackness B, Mackness M, Riu F, Beltrán R, Joven J, Camps J: Immunohistochemical analysis of paraoxonases-1, 2, and 3 expression in normal mouse tissues. Free Radic Biol Med 2008, 45:146-157.

35. Deakin SP, Bioletto S, Bochaton-Piallat M-L, James RW: HDL-associated paraoxonase-1 can redistribute to cell membranes and influence sensitivity to oxidative stress. Free Radic Biol Med 2011, 50:102-109.

36. Ozer EA, Pezzulo A, Shih DM, Chun C, Furlong C, Lusis AJ, Greenberg EP, Zabner J: Human and murine paraoxonase 1 are host modulators of Pseudomonas aeruginosa quorum-sensing. FEMS Microbiol Lett 2005, 253:29-37.

37. Stoltz DA, Ozer EA, Ng CJ, Yu JM, Reddy ST, Lusis AJ, Bourquard N, Parsek MR, Zabner J, Shih DM: Paraoxonase-2 deficiency enhances Pseudomonas aeruginosa quorum sensing in murine tracheal epithelia. Am J Physiol Lung Cell Mol Physiol 2007, 292:L852-L860.

38. Draganov DI, La Du BN: Pharmacogenetics of paraoxonases: a brief review. Naunyn Schmiedebergs Arch Pharmacol 2004, 369:78-88.

39. Stevens RC, Khateeb J, Rock W, Draganov DI, Qureshi MM, Noll C, Sierksma A, Suzuki SM, Gantman A, Rosenblat M, MD RGO, Noll C, van der Gaag MS, Cole TB, Kreitenberg AJ, Miller-Lotan R, McClure WC, Messaoudi S, van Tol A, Park SS, Aviram M, Levy AP, C-PNP JVSM, Messaoudi S, James RW, Richter RJ, Fuhrman B, Elias M, Arevalo NL, Milliez P, et al: Engineered recombinant human paraoxonase 1 (rHuPON1) purified from Escherichia coli protects against organophosphate poisoning. Proc Natl Acad Sci 2008, 105:12780-12784.

40. Davies HG, Richter RJ, Keifer M, Broomfield CA, Sowalla J, Furlong CE: The effect of the human serum paraoxonase polymorphism is reversed with diazoxon, soman and sarin. Nat Genet 1996, 14:334-336.

41. Teslovich TM, Musunuru K, Smith AV, Edmondson AC, Stylianou IM, Koseki M, Pirruccello JP, Ripatti S, Chasman DI, Willer CJ, Johansen CT, Fouchier SW, Isaacs A, Peloso GM, Barbalic M, Ricketts SL, Bis JC, Aulchenko YS, Thorleifsson G, Feitosa MF, Chambers J, Orho-Melander M, Melander O, Johnson T, Li X, Guo X, Li M, Shin Cho Y, Jin Go M, Jin Kim Y, et al: Biological, clinical and population relevance of 95 loci for blood lipids. Nature 2010, 466:707-713.

42. Kris-Etherton PM: Fish consumption, fish Oil, omega-3 fatty acids, and cardiovascular disease. Circulation 2002, 106:2747-2757.

43. Kim DS, Burt AA, Ranchalis JE, Jarvik ER, Rosenthal EA, Hatsukami TS, Furlong $C E$, Jarvik GP: Novel gene-by-environment interactions: $A P O B$ and NPC1L1 variants affect the relationship between dietary and total plasma cholesterol. J Lipid Res 2013, 54:1512-1520.

\section{Submit your next manuscript to BioMed Central and take full advantage of:}

- Convenient online submission

- Thorough peer review

- No space constraints or color figure charges

- Immediate publication on acceptance

- Inclusion in PubMed, CAS, Scopus and Google Scholar

- Research which is freely available for redistribution 